\title{
MAPEAMENTO DE NEMATOIDES NA CULTURA CAFEEIRA A PARTIR DE IMAGENS MULTIESPECTRAIS OBTIDAS POR AERONAVES REMOTAMENTE PILOTADAS
}

\author{
Carlos Alberto Matias de Abreu Júnior \\ Universidade Federal de Uberlândia, Pós-graduação em Agricultura e Informações Geoespaciais, Monte \\ Carmelo, MG, Brasil \\ carlosalberto0103@hotmail.com
}

Geovane Piveta Vinhal Universidade Federal de Uberlândia, Instituto de Geografia, Graduação em Engenharia de Agrimensura e Cartográfica, Monte Carmelo, MG, Brasil geovanepiveta@hotmail.com

Laura Cristina Moura Xavier Universidade Federal de Uberlândia, Instituto de Geografia, Graduação em Engenharia de Agrimensura e Cartográfica, Monte Carmelo, MG, Brasil xavier.lauramoura@gmail.com

George Deroco Martins Universidade Federal de Uberlândia, Faculdade de Engenharia Civil - FECIV, Monte Carmelo, MG, Brasil deroco@ufu.br

Bruno Sérgio Vieira Universidade Federal de Uberlândia, Instituto de Ciências Agrárias, Monte Carmelo, MG, Brasil brunovieira@ufu.br

\section{RESUMO}

O sensoriamento remoto vem sendo aplicado cada vez mais na agricultura de precisão, devido a sua forte correlação com variáveis agrícolas. A combinação espectral de bandas do visível vem se tornando uma alternativa em câmeras com ausência do infravermelho próximo, devido a uma relativa correlação com a vegetação e, consequentemente, com as variáveis agrícolas. Assim, é possível identificar alterações presentes na plantação devido ao ataque de pragas e patógenos, sendo detectável a presença de nematoides na cultura cafeeira com essa ferramenta. Nesse contexto, as Aeronaves Remotamente Pilotadas (ARPs) de baixo custo possibilitam monitoramento contínuo dessas culturas, sendo uma alternativa utilizada para a geração de mapas de manejo de pragas e patógenos, auxiliando no monitoramento da produtividade dos cultivos, minimizando perdas. Neste trabalho, foi utilizada a classificação pelo método de máxima verossimilhança para discriminação de áreas da cultura cafeeira infestada por nematoides. Para tanto, a classificação foi aplicada em combinação de bandas do visível com NDVI e a análise da acurácia do mapeamento foi validada a partir do índice Kappa. A Matriz de confusão apresentou $20 \%$ de erro de omissão (para nematoide) e $28,57 \%$ de comissão (para solo exposto), sendo estes os maiores valores obtidos, além do índice Kappa de 0,75.

Palavras-chave: Cafeicultura. Agricultura de Precisão. Índices de vegetação. Mapas de infestação.

\section{MAPPING OF NEMATODES IN COFFEE CULTURE FROM MULTISPECTRAL IMAGES OBTAINED BY REMOTELY PILOT AIRCRAFT}

\begin{abstract}
Remote sensing has been increasingly applied in precision agriculture due to its strong correlation with agricultural variables. The spectral combination of visible bands has become an alternative cameras with absence of near infrared, due to a relative correlation with the vegetation and, consequently, with the agricultural variables. In this way it is possible to identify changes present in a plantation due to pest and pathogen attack, being possible to detect the presence of nematodes in the coffee crop with this tool. In this context low-cost remotely piloted aircraft (RPAS) allow the continuous monitoring of these crops being an increasingly used alternative for the generation of pest/pathogens management maps,
\end{abstract}

$\begin{array}{lllll}\text { Caminhos de Geografia } \quad \text { Uberlândia-MG } & \text { v. 21, n. } 76 & \text { Ago/2020 } & \text { p. 72-84 } & \text { Página } 72\end{array}$


assisting in monitoring productivity of the plantations, minimizing losses. In this work, the classification by the maximum likelihood method was used to discriminate areas of the coffee crop infested by nematodes. For this, the classification was applied in a combination of Normalized Difference Vegetation Index and analysis of the accuracy of the mapping was validated from the Kappa index. The confounding matrix presented $20 \%$ omission error (for nematode), $28.57 \%$ commission (for exposed soil), being the highest values obtained, in addition to the Kappa index of 0.75 .

Keywords: Coffee growing. Precision agriculture. Vegetation index. Infestation maps.

\section{INTRODUÇÃO}

A produção de café impulsiona fortemente as atividades de indústria e comércio do Brasil, assim como gera uma gama de empregos nas regiões onde ocorre sua produção. Essa variedade de regiões produtoras e a extensão dessas áreas fazem com que o Brasil seja o maior produtor mundial de café e o segundo maior mercado consumidor (ARRUDA, 2017). A projeção realizada pelo Conselho dos Exportadores de Café do Brasil (Cecafé), aponta que até 2030 o consumo mundial deve aumentar por volta de 30\% e atingir 204,65 milhões de sacas. Assim, para que o Brasil conserve sua parcela de mercado, é necessário que a produção nacional aumente por volta de 16,17 milhões de sacas até 2030 (EMBRAPA, 2018).

Com o aumento da produtividade aliado à tecnologia, existem diversos fatores que podem causar a redução da produtividade e redução da área plantada de café. Entre eles, os aspectos relacionados à ocorrência de pragas e doenças durante o ciclo da cultura estão entre os mais significativos. Dentre os diversos fatores que causam sérios prejuízos e principalmente perdas na produtividade na cultura do café estão os fitonematoides, onde os pertencentes ao gênero Meloidogyne, conhecidos como nematoides de galhas têm maior destaque (ITO, 2012).

Dezessete espécies de fitonematoides do gênero Meloidogyne podem estar associadas a raízes do cafeeiro. Meloidogyne incognita, M. paranaensis, $M$. cofeiicola e $M$. exigua são as que causam os maiores danos ao cafeeiro. (ZAMBOLIM, 2016). No Brasil, M. incognita, M. paranaensis e M. exigua constituem as principais espécies pelos danos que causam e pela ampla distribuição nas áreas produtoras de café (CAMPOS e VILLAIN, 1990. Os fitonematoides danificam drasticamente a integridade das raízes do cafeeiro, podendo causar galhas arredondadas em raízes mais novas e superficiais, após as primeiras chuvas da primavera, como observado em infecções de $M$. exigua e causar descortiçamento das raízes, escamações na superfície de raízes, com aspecto de cortiça, com descascamento, rachaduras e pontos de lesões necróticas, manifestado por infecções de $M$. incognita e M. paranaensis. Na parte aérea das plantas, os sintomas são clorose, desfolhamento, seca de ramos plagiotrópicos, redução no crescimento e, em alguns casos, morte da planta (FERRAZ, 2012).

Quando se objetiva o aumento de produtividade e busca de qualidade é imprescindível que haja inicialmente a diminuição das perdas causadas por fitopatógenos e pragas, sendo a agricultura de precisão uma das soluções para tais desafios. Nos últimos anos, o sensoriamento remoto, que possibilita obtenção de informações sobre alvos na superfície terrestre, sem contato com estes, tornouse uma importante ferramenta no âmbito da agricultura de precisão e monitoramento agrícola, tendo o objetivo de manejo diferenciado de áreas agrícolas por meio da aplicação diferenciada de práticas agronômicas a partir de uma definição prévia da distribuição espacial das condições da cultura (MARTINS e GALO, 2015).

Nas atividades agrícolas, o sensoriamento remoto tem-se destacado devido à forte correlação de imagens com as variáveis agrícolas, visando auxiliar práticas de planejamento de plantio e diversos tipos de monitoramento. No Brasil, há diversos estudos quem permeiam aplicações do Sensoriamento Remoto em atividades agrícolas. Oliveira (2015) estimou a produtividade de cana-de-açúcar em função de índices de vegetação a partir de dados multiespectrais. Martins e Galo (2014; 2015) detectaram áreas agrícolas com cana-de-açúcar infestadas por nematoides. No primeiro trabalho, os autores utilizaram a espectrorradiometria no visível e infravermelho próximo para a detecção de áreas infestadas por nematoides, e no segundo os mesmos autores geraram mapas de variabilidade do

$\begin{array}{lllll}\text { Caminhos de Geografia } \quad \text { Uberlândia-MG } & \text { v. 21, n. } 76 \quad \text { Ago/2020 } & \text { p. 72-84 } & \text { Página } 73\end{array}$


potencial de produtividade obtidos por plataformas orbitais. Beck et al. (2015) verificaram o potencial de sensores instalados em plataformas orbitais na detecção de nematoides na cultura de pinheiros.

Contudo, um dos fatores que tem impulsionado o sensoriamento remoto fortemente na agricultura de precisão são as Aeronaves Remotamente Pilotadas (ARPs), que possibilitam o monitoramento contínuo das plantações agrícolas, auxiliando nos processos de tomada de decisão nos principais meios agronômicos. A velocidade de disseminação desta tecnologia, o baixo custo, a facilidade operacional, e a interação direta entre o produtor e imagem têm a tornado a ferramenta mais difundida no processo de tomadas de imagem para a agricultura de precisão (DAMIAN et al., 2016).

Em termos comerciais, as imagens tomadas por ARPs são definidas como produtos confiáveis e precisos. Porém, há uma série de questionamentos que precisam ser avaliados quanto à potencialidade de tais imagens no monitoramento de condições específicas das culturas agrícolas, considerando a geométrica de aquisição de dados por plataformas aéreas, as resoluções espacial e espectral dos sensores de imageamento e a escala do produto.

Dessa forma, esta pesquisa teve o objetivo de avaliar o potencial de imagens multiespectrais obtidas por ARPs para detecção de nematoides na cultura cafeeira. Em termos gerais, foi avaliado a interferência do GSD (Ground Sample Distance) na detecção das áreas infestadas, uma vez que, em imagens com maior resolução espacial, é possível discriminar visualmente os alvos de forma mais acurada. Para subsidiar os resultados encontrados nesta pesquisa foi calculada a matriz de confusão, assim como o índice Kappa, criado por Cohen (1960).

\section{MATERIAL E MÉTODOS}

\section{Área de estudo e materiais utilizados}

A área de estudo está localizada nas imediações da área urbana do município de Monte Carmelo-MG, situado na mesorregião do Triângulo Mineiro e Alto Paranaíba (Figura 1). A área abrange cerca de três hectares e consiste em um talhão de uma cultura cafeeira com comprovada presença de nematoides da espécie M. exigua.

Figura 1 - Mapa de Localização: (A) Município de Monte Carmelo em destaque no mapa de Minas Gerais e Brasil. (B) Talhão de café destacando a área de estudo em uma composição cor natural RGB de uma imagem aerofotogramétrica, limitada no vermelho.
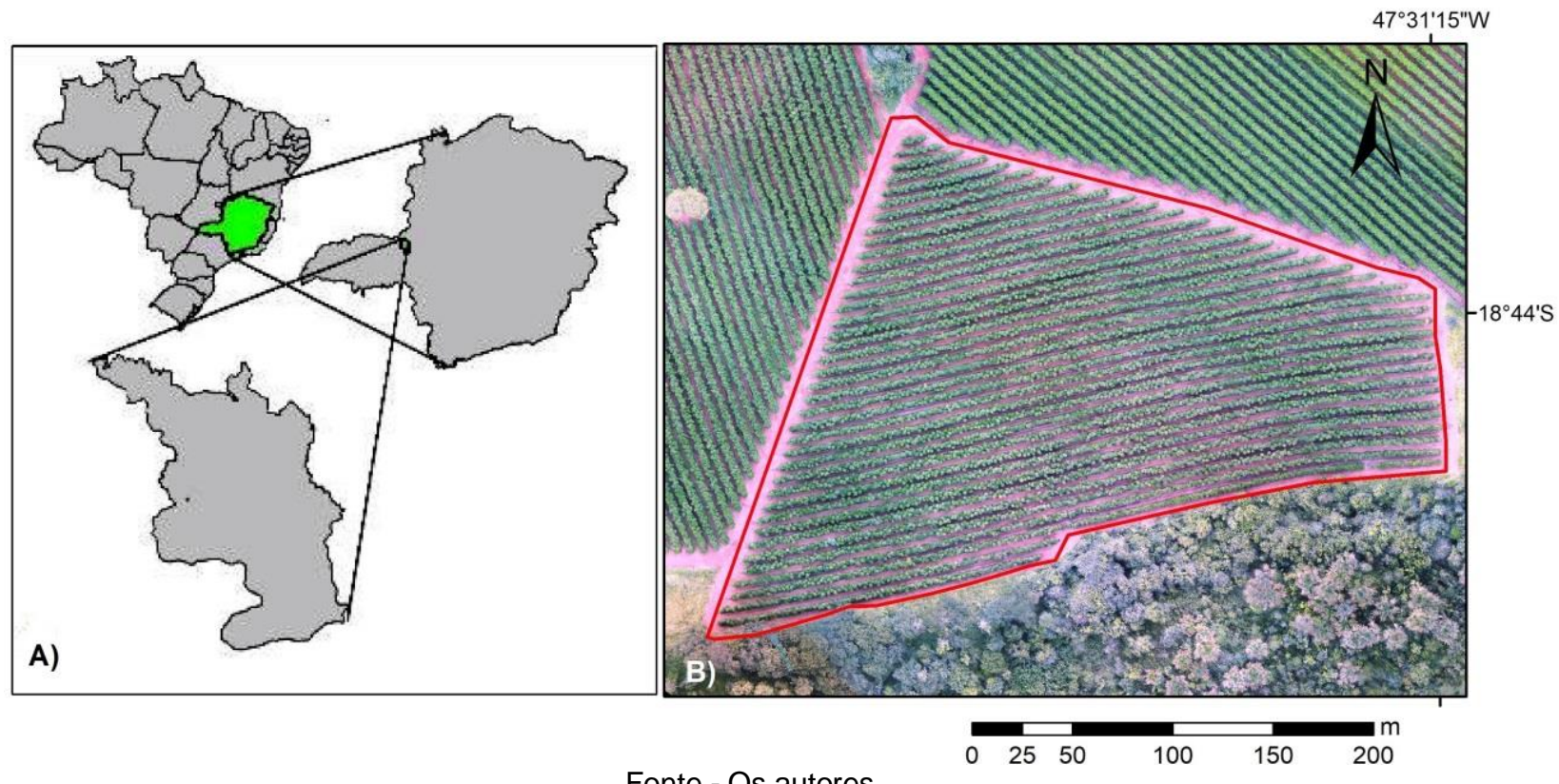

Fonte - Os autores. 
Os materiais utilizados para o desenvolvimento desta pesquisa foram:

- Cartolinas para a pré-sinalização dos alvos coloridos, que foram utilizadas para a identificação dos alvos na etapa de calibração radiométrica da imagem;

- GPS de Navegação Portátil Garmin GPSMAP 73, para medir as coordenadas em campo dos alvos espectrais estudados, a fim de construir os seus respectivos arquivos shapfile posteriormente;

- Drone Phantom 4 Advanced, com GPS Integrado e equipado com um sensor Mapir, operando nas regiões vermelho, verde e infravermelho próximo do espectro eletromagnético, além da sua câmera padrão, com sensor CMOS, focal de $20 \mathrm{~mm}$ e 20 megapixels, que registra imagens no canal do visível. Ambos sensores foram destinados a captura das imagens da área de estudo;

- Software Pix4Dmapper para a geração do mosaico das imagens obtidas pelo drone (software comercial - versão teste);

- Software MAPIR Câmera Control para a calibração radiométrica (software livre);

- Software ENVI Classic 5.0 para aplicação das técnicas de pré-processamento, técnicas de realce, classificação e extração dos valores radiométricos, assim como o cálculo do NDVI (software comercial - licença número 1201671);

- Software ArcGIS 10.1 para a confecção dos mapas temáticos (software comercial - licença número EFL515599307).

\section{AQUISIÇÃO DOS DADOS EM CAMPOS E PRÉ-PROCESSAMENTO DA IMAGEM}

No talhão de estudo foram investigadas in situ três classes de informação: solo exposto, plantas de cafeeiro sadias e infectadas por nematoides. Com um receptor de navegação, foram georreferenciados locais que serviram de apoio para a classificação de imagens e para análise da acurácia do mapeamento.

As imagens foram tomadas a partir de dois sensores, sendo eles: uma câmera Mapir 3 , acoplada à ARP (Phanton 4), que captura os comprimentos de onda do verde, vermelho e infravermelho próximo, além do sensor padrão da câmera acoplada ao drone, que processa a radiação proveniente dos canais azul, verde e vermelho.

Inicialmente, no pré-processamento da imagem, foi feito a calibração radiométrica, executada através do software MAPIR Câmera Control, sendo utilizados os alvos coloridos (branco, preto, vermelho, verde e azul) dispostos em pontos estratégicos in situ, para a posterior identificação na imagem. Esse processamento foi feito utilizando o mosaico final das imagens, e não as imagens separadas, como é descrito no manual de utilização do software, devido a possíveis falhas que podem ocorrer no processo de calibração. A calibração radiométrica foi realizada apenas para o mosaico proveniente da câmera Mapir 3.

O método consistiu em detectar, em cada banda envolvida, as regiões mais claras (com alta intensidade e baixa saturação) e as mais escuras (com baixa intensidade e alta saturação). Os valores de reflectância conhecidos, ou seja, os valores dos alvos implantados foram necessários para a geração dos valores de calibração, que em seguida foram comparados com os valores do mosaico, transformando os pixels e calibrando as imagens do levantamento. Para melhor entendimento, o alvo preto dispõe do valor máximo de reflectância, enquanto o branco do valor mínimo, e quando comparados com outras cores, estas seriam o valor máximo perante o alvo branco, e quando analisada perante o alvo preto, o valor seria o mínimo na imagem.

\section{REGISTRO DE IMAGENS}

As imagens produzidas por sensores remotos, sejam elas fotografias aéreas ou imagens de satélite, apresentam uma série de distorções espaciais, não possuindo, portanto, precisão cartográfica quanto ao posicionamento dos objetos, superfícies ou fenômenos nelas representados. Por esse motivo, fezse necessário o registro de imagem, e logo ainda, devido a fundamentação desse trabalho se basear na captura de imagens aéreas por meio de dois sensores embarcados em uma mesma plataforma, tal 
técnica foi fundamental para que as imagens se tornassem georreferenciadas entre si e ser possível a utilização das mesmas amostras de fornecimento prévio para o treinamento do algoritmo de classificação.

Essa etapa se baseou no registro de "uma imagem para outra imagem", utilizada quando existe uma imagem georreferenciada da mesma área. A imagem base foi definida pela RGB, enquanto que a imagem distorcida a Mapir 3 , definindo ainda como tipo de reamostragem a transformação polinomial, devido a determinação de cinco pontos de controle, e assim definido também como quatro grau do polinômio.

Após feito o registro de imagem, foi importante notar o erro advindo de tal procedimento. Denominado erro médio quadrático, é uma medida do desvio dos valores calculados em relação aos valores originais. O erro RMSE foi estimado tomando-se uma amostra dos valores calculados e comparandoa com seus valores reais. As diferenças entre elas foram elevadas ao quadrado e somadas. A soma foi então dividida pelo número de medidas, para que se obtivesse a média cuja raiz quadrada fornecesse uma medida característica de erro na mesma unidade das medidas originais. O erro RMS é diretamente comparável ao conceito de desvio padrão, e pode ser observado pela equação 1.

$$
\text { RMSerror }=\sqrt{\left(x_{r}-x_{i}\right)^{2}+\left(y_{r}-y_{i}\right)^{2}}
$$

\section{Onde:}

- $\quad x_{r}$ é a coordenada de linha calculada na imagem não-registrada;

- $\quad y_{r}$ é a coordenada de coluna calculada na imagem não-registrada;

- $x_{i}$ é a coordenada original de linha do GCP (Ground Control Points) na imagem;

- $y_{i}$ é a coordenada original de coluna do GCP na imagem.

Esse erro não interferiu na sequência das etapas, pois foi considerado mínimo, pois o deslocamento de uma imagem para outra foi de somente 1,21 centímetros.

\section{CLASSIFICAÇÃO DE IMAGENS}

Após a calibração e registro, foram obtidos três arquivos vetoriais com parte das coordenadas mensuradas em campo, discriminadas em relação às classes de informação, sendo elas: plantas de cafeeiro sadias e infectadas e solo exposto. Estes arquivos foram utilizados como amostras para as regiões de interesse, as quais foram necessárias para o treinamento do algoritmo, na fase de definição das classes, para a classificação da imagem pelo método Máxima Verossimilhança.

A classificação supervisionada pelo método de máxima verossimilhança é considerada paramétrica, uma vez que os parâmetros utilizados, valor da média e matriz de covariância, pertencem à distribuição gaussiana, e possui o caráter supervisionado por estimar seus valores utilizando amostras de treinamento (QUEIROZ; RODRIGUES; GÓMEZ, 2004). Neste processo, o algoritmo funciona através da ponderação das distâncias existentes entre as médias dos valores de referência das respectivas classes, embasando-se através de parâmetros estatísticos. A repartição dos valores de reflectância das classes, destinadas ao treinamento do algoritmo, são representadas por uma função de densidade de probabilidade. Dessa forma, os pixels são verificados um a um, de modo a verificar a probabilidade de este pertencer a uma determinada classe, através de sua probabilidade de associação (INPE, 2002).

Diante disto, foram definidos os dados de entrada para o processo de classificação. Os atributos para o treinamento do algoritmo foram compostos pelas bandas originais da Câmera Mapir 3 e o índice de vegetação derivado NDVI (Normalized Difference Vegetation Index). adquirida pela câmera Mapir 30 índice NDVI mede a intensidade da vegetação, sendo amplamente utilizado em práticas relacionadas à agricultura de precisão. Os valores da imagem resultante variam de -1 a 1 , sendo que quanto mais próximo de 1 maior é o vigor da vegetação local, e quanto mais próximo de -1 , menor a presença de vegetação, representando um baixo teor ou nulo de clorofila (SILVA et al., 2018). O NDVI foi determinado pela equação 2 : 


$$
N D V I=\frac{N I R-R}{N I R+R}
$$

Onde: $\mathrm{NIR}=$ banda do infravermelho próximo e o $\mathrm{R}=$ banda do vermelho.

Para o mosaico RGB foi calculado o TGI, a fim de auxiliar o treinamento do algoritmo durante a classificação. Segundo McKinnon e Hoff (2017) podemos descrever a equação do TGI (Triangular Greenness Index) conforme equação 3:

$T G I=G-0,39 * R-0,61 * B$

Onde $G$ são os valores espectrais do canal verde, $R$ os valores espectrais do canal vermelho e $B$ os valores espectrais do canal azul.

Para as classificações, os dados a serem processados foram definidos da seguinte forma: Classificação 1- bandas originais Mapir 3 e o NDVI e; Classificação 2- bandas originais da câmera do Phanton 4 e índice TGI.

Com o auxílio de um GPS de navegação portátil foram georreferenciados pontos para o apoio para localizar as amostras de treinamento da classificação e para a verificação da acurácia do mapeamento. Tais pontos são apresentados na Figura 2.

Figura 2 - Distribuição espacial dos pontos mensurados in situ.

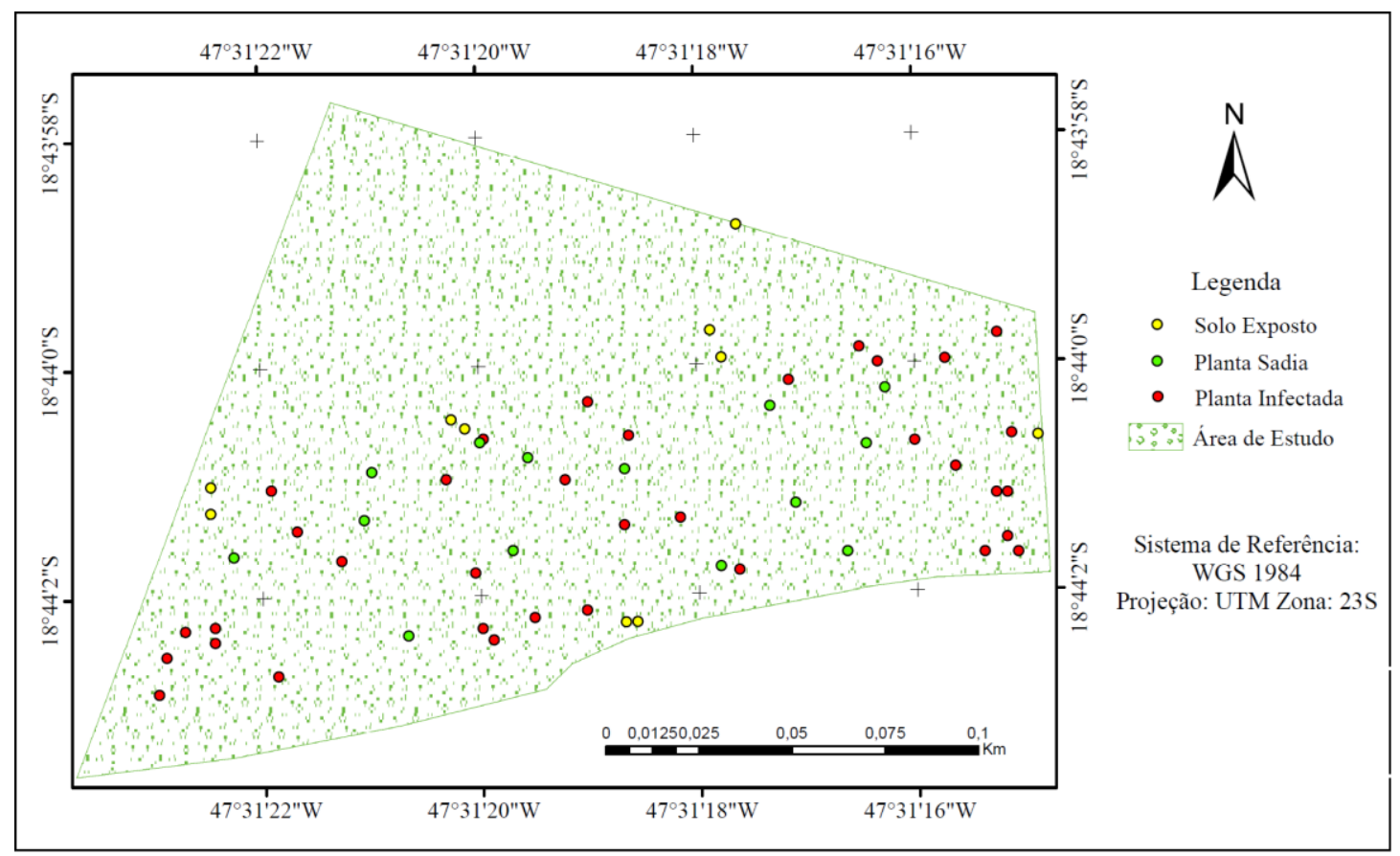

Fonte - Os autores.

Os pontos mensurados na Figura 2 foram divididos em duas partes, a partir da primeira, criou-se então três arquivos shapefile, para serem utilizados como amostras para as regiões de interesse. Esse procedimento foi feito para a definição de cada classe, a fim de se realizar o treinamento do algoritmo, e assim tornar possível a classificação das imagens. A segunda parte, contendo os pontos restantes, foram utilizados para criar amostras a serem aplicadas na validação da classificação, por meio da matriz de confusão, coeficiente Kappa e do índice de exatidão global. No total foram utilizados 23 pontos amostrais no treinamento do algoritmo para a classificação e 44 pontos para a validação do mapeamento. 

Bruno Sérgio Vieira

Para avaliar a acurácia dos mapeamentos foi calculado o índice Kappa, sugerido por Cohen (1960), que serve para validar classificações. $O$ índice foi calculado através da matriz de confusão, que retorna também o valor da acurácia geral da classificação.

Além do índice Kappa, também foram calculadas a matriz de confusão e acurácia global. Segundo Kohavi e Provost (1998), a matriz de confusão contém informações referentes ao número de classes atuais e previstas, que implicaram na veracidade dos dados analisados ou não. No contexto dos classificadores esses valores são usados para determinar o número de valores classificados incorretamente, assim como os que foram devidamente classificados.

\section{RESULTADOS E DISCUSSÃO}

\section{DISTRIBUIÇÃO DAS AMOSTRAS}

Para subsidiar os resultados das classificações, justificar o uso de um classificador paramétrico, assim como compreender a estrutura lógica e sequencial executada pelo algoritmo classificador, foram feitos gráficos de distribuição de probabilidade para as amostras utilizadas durante o treinamento do algoritmo (Figuras 3 e 4). Foram analisados os valores de reflectância referentes a cada banda dos mosaicos, assim como os seus respectivos índices de vegetação.

Figura 3 - Gráficos de distribuição normal para as amostras de estudo na imagem RGB.
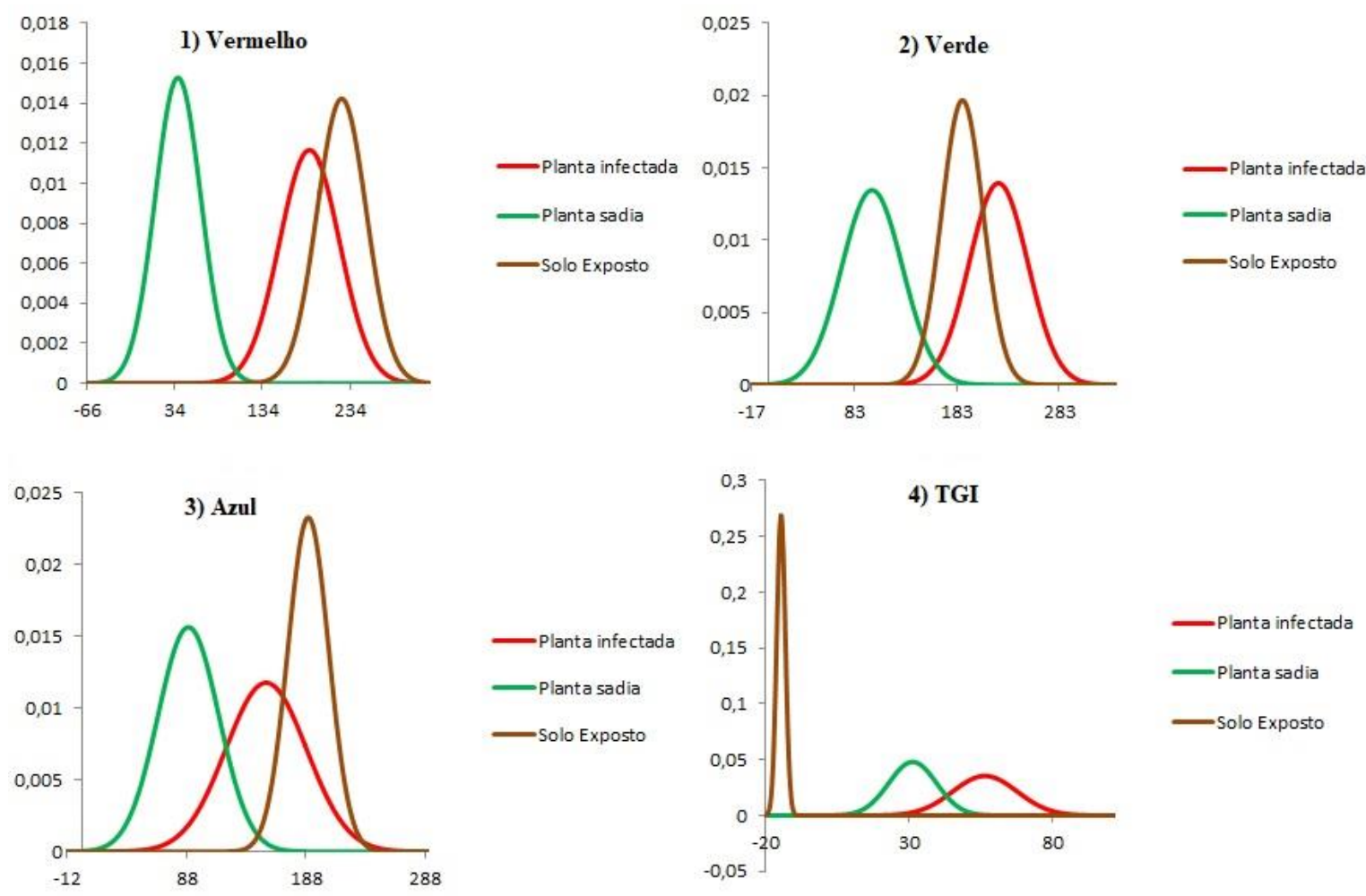

Fonte - Os autores.

Na Figura 3, os gráficos 1, 2 e 3 representam a distribuição normal das bandas do espectro visível (vermelho, verde e azul respectivamente) e o gráfico 40 índice TGl. As cores atribuídas às curvas foram associadas às cores das classes utilizadas na classificação, sendo vermelho para cafeeiro infectado por nematoide, verde para cafeeiro saudável e marrom para solo exposto. 

Bruno Sérgio Vieira

Ao analisar o comportamento da distribuição nas bandas referentes à resposta espectral do espectro visível, nota-se separação entre as informações das plantas sadias e as infectadas por nematoides, com separação maior nas bandas do vermelho e do verde. Em contrapartida, observa-se certa proximidade das classes - plantas infectadas e solo exposto, o que poderia causar certa confusão no algoritmo. Entretanto, estas classes são muito bem separadas no TGI, o que contribui para melhorar a acurácia do classificador.

Figura 4 - Gráficos de distribuição normal para as amostras de estudo na imagem RGN.
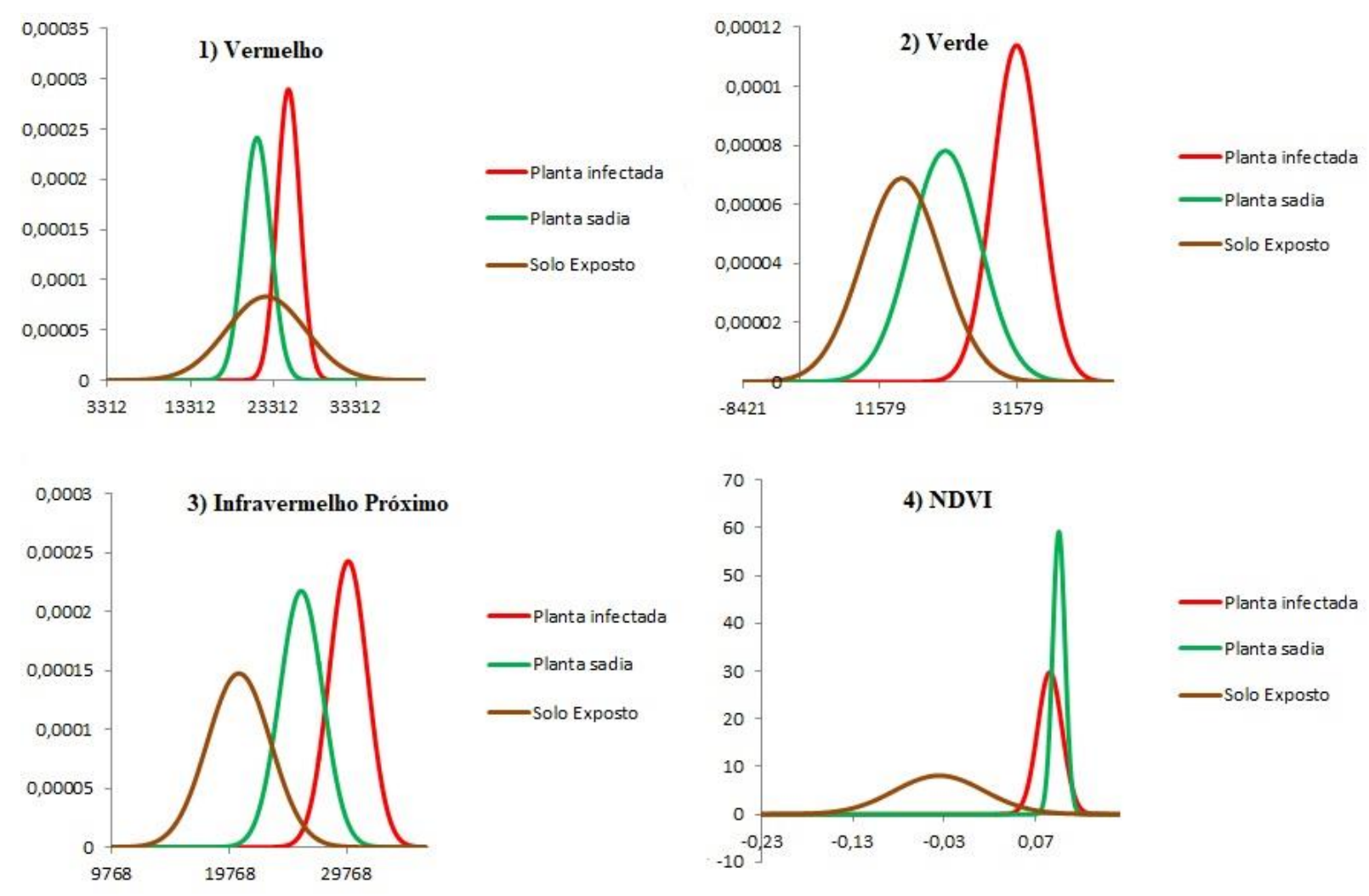

Fonte - Os autores.

A Figura 4 segue o mesmo padrão para associação de cores e classes que a Figura 3. Ao comparar os resultados obtidos entre as quatro fontes de dados, é possível notar que existe uma maior discriminação entre as classes na banda do infravermelho próximo. Neste contexto, o índice de vegetação não se mostrou efetivo para a separação das classes cafeeiro sadio e infectado por nematoides, sendo a maior separação feita entre as duas classes em relação ao solo exposto.

\section{CLASSIFICAÇÃO MAXVER}

A Figura 5 mostra o resultado obtido pela classificação supervisionada pelo método de máxima verossimilhança para os dados de entrada formados pela união das bandas convencionais da câmara acoplada ao drone e o índice TGl. 
Figura 5 - Distribuição espacial do cafeeiro sadio e infectado por nematoides, gerado através da classificação supervisionada pelo método máxima verossimilhança dos dados de entrada câmera RGB e índice TGI.

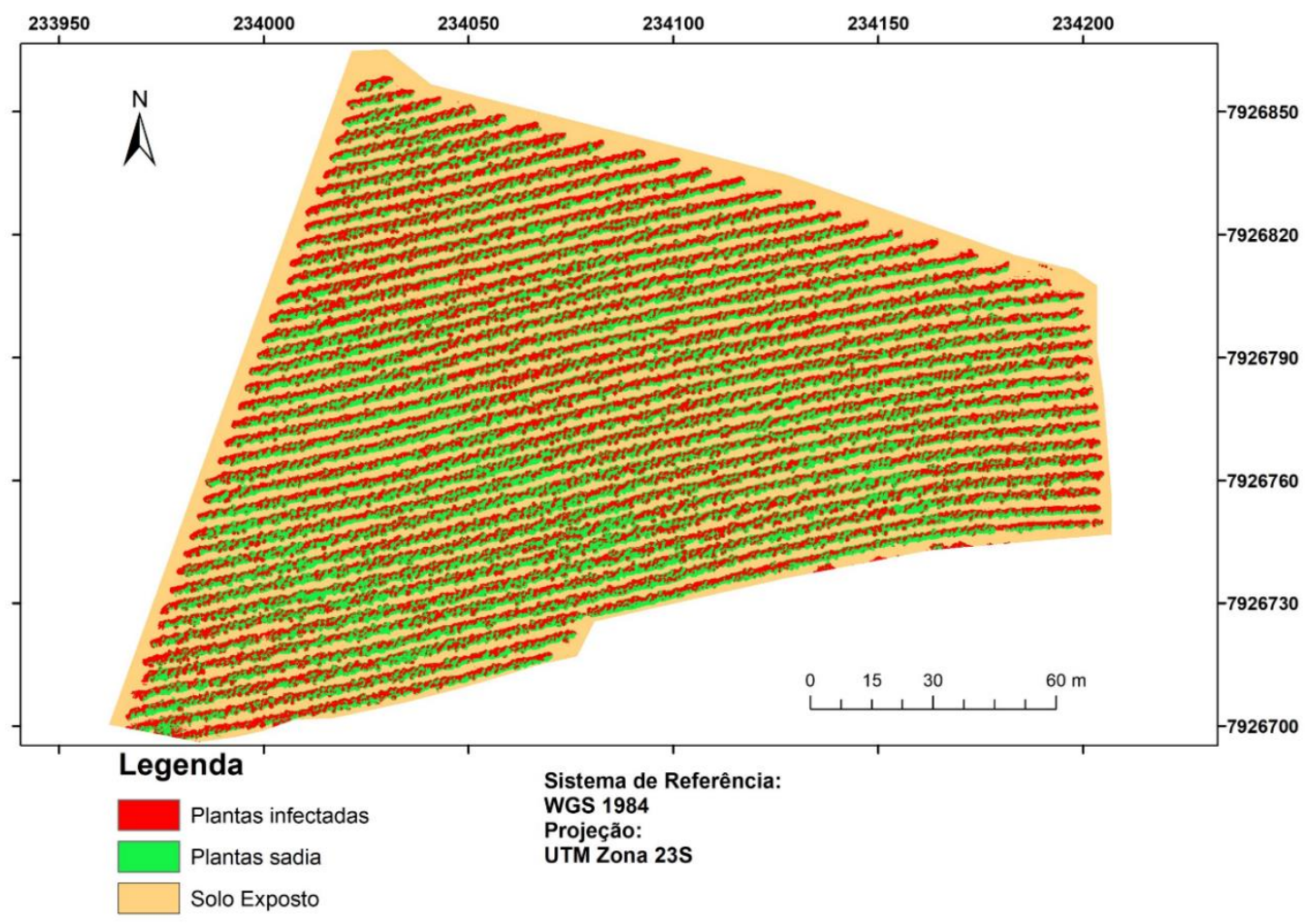

Fonte - Os autores.

Na Figura 5 as classes são representadas pelas cores vermelho (plantas infectadas), verde (plantas sadias) e Magenta (solo exposto). Nota-se que a discriminação dos alvos espectrais foi obtida de forma correta pelo algoritmo classificador. No mapa, o comportamento das áreas infestadas por nematoides apresenta alguns focos com característica transversal, na qual é possível destacar sua maior intensidade nas regiões periféricas e na parte central da imagem, seguindo de forma alternada com plantas de cafeeiro sadias. O solo exposto foi corretamente classificado, uma vez que é possível observá-lo entre as linhas de plantio e nas bordas da imagem.

A Tabela 1 apresenta os resultados obtidos pela matriz de confusão, confrontantes com a verdade de campo. Nela estão representados as classes de informação, assim como a taxa de comissão e omissão referentes a cada amostra, variando em porcentagem. Ao todo foram analisados 44 pontos de controle.

Tabela 1 - Matriz de confusão para a classificação MAXVER com os erros de comissão e omissão para imagem RGB.

\begin{tabular}{|c|c|c|c|c|c|}
\hline Classe & $\begin{array}{l}\text { Plantas } \\
\text { sadias }\end{array}$ & $\begin{array}{c}\text { Plantas } \\
\text { infectadas }\end{array}$ & Solo Exposto & Total & Comissão (\%) \\
\hline $\begin{array}{l}\text { Plantas } \\
\text { sadias }\end{array}$ & 12 & 3 & 0 & 15 & 20 \\
\hline $\begin{array}{l}\text { Plantas } \\
\text { infectadas }\end{array}$ & 1 & 15 & 1 & 17 & 11,76 \\
\hline Solo Exposto & 1 & 2 & 9 & 12 & 25 \\
\hline Total & 14 & 20 & 10 & 44 & \\
\hline Omissão (\%) & 14,28 & 25,00 & 10,00 & & \\
\hline
\end{tabular}

Fonte - Os autores.

\begin{tabular}{|c|c|c|c|c|}
\hline Caminhos de Geografia & Uberlândia-MG & v. 21, n. 76 & $\mathrm{Ago} / 2020$ & p. 72-84 \\
\hline
\end{tabular}


Observa-se que a classe que obteve menores valores para erro de omissão foi a classe solo exposto $(10,00 \%)$, sendo que apenas um ponto de controle dentre os 10 analisados foi classificado incorretamente (Tabela 1). Esse erro pode ser justificado em análise conjunta com a Figura 3, que mostra que nas bandas do comprimento de onda do visível as curvas de normalidade das classes solo exposto e plantas infectadas apresentam-se próximas. A classe 'Plantas sadias' apresentou resultados intermediários dentre as 3 analisadas (14,28\%), sendo que houve apenas dois pontos de controle classificados erroneamente. Dessa forma, os maiores erros foram apresentados pela classe 'Plantas infectadas' $(25,00 \%)$, sendo que três pontos de controle foram classificados como 'Plantas sadias', e dois como solo exposto.

Com relação ao desempenho do usuário na determinação das classes, o maior erro de comissão foi na classe solo exposto ( $25 \%$ ), seguida pela classe 'Plantas sadias' $(20 \%)$ e por último, com o menor erro de comissão apresentado a classe 'Plantas infectadas' (11,76\%). Esses valores constatam-se com os referentes ao erro de omissão, onde a ordem do melhor para o pior foi inversa. Analisando os pontos de controle que foram classificados de forma errônea segundo o erro de comissão, mais uma vez observa-se a confusão entre pontos de solo exposto com a classe "Plantas infectadas', o que pode ser remetido mais uma vez a aproximação dessas classes (Figura 3).

Essas confusões justificam-se também pela ausência de uma banda multiespectral, com comprimentos de onda do infravermelho próximo, que é onde a vegetação é bem discriminada e refletida com maior intensidade. Segundo Ponzoni; Shimabukuro; Kuplich (2012), um fator que prejudica a reflectância das bandas do comprimento de onda do visível sobre a vegetação é a presença de água, que tem facilidade para absorver radiações e, consequentemente, reduzir o fluxo de energia refletida.

O índice Kappa e a acurácia global apresentaram valores de 0,72 e 81\% respectivamente. Confrontando o valor do Kappa calculado com os intervalos apresentados na tabela de referência, a classificação pode ser definida como "muito boa". Da mesma forma, a acurácia global também apresentou um resultado considerável, sendo este acima de $80 \%$.

O mapa temático gerado através da imagem multiespectral Mapir 3 em junção com a banda oriunda do cálculo NDVI é mostrado na Figura 6. Neste mapa as classes foram discriminadas entre cafeeiro infectados por nematoides, cafeeiros sadios e solo exposto.

Figura 6 - Distribuição espacial de cafeeiros sadios e infectados por nematoides, gerado através da classificação supervisionada pelo método da máxima verossimilhança através dos dados de entrada formado pelas bandas originais da câmera Mapir 3 e o índice NDVI.

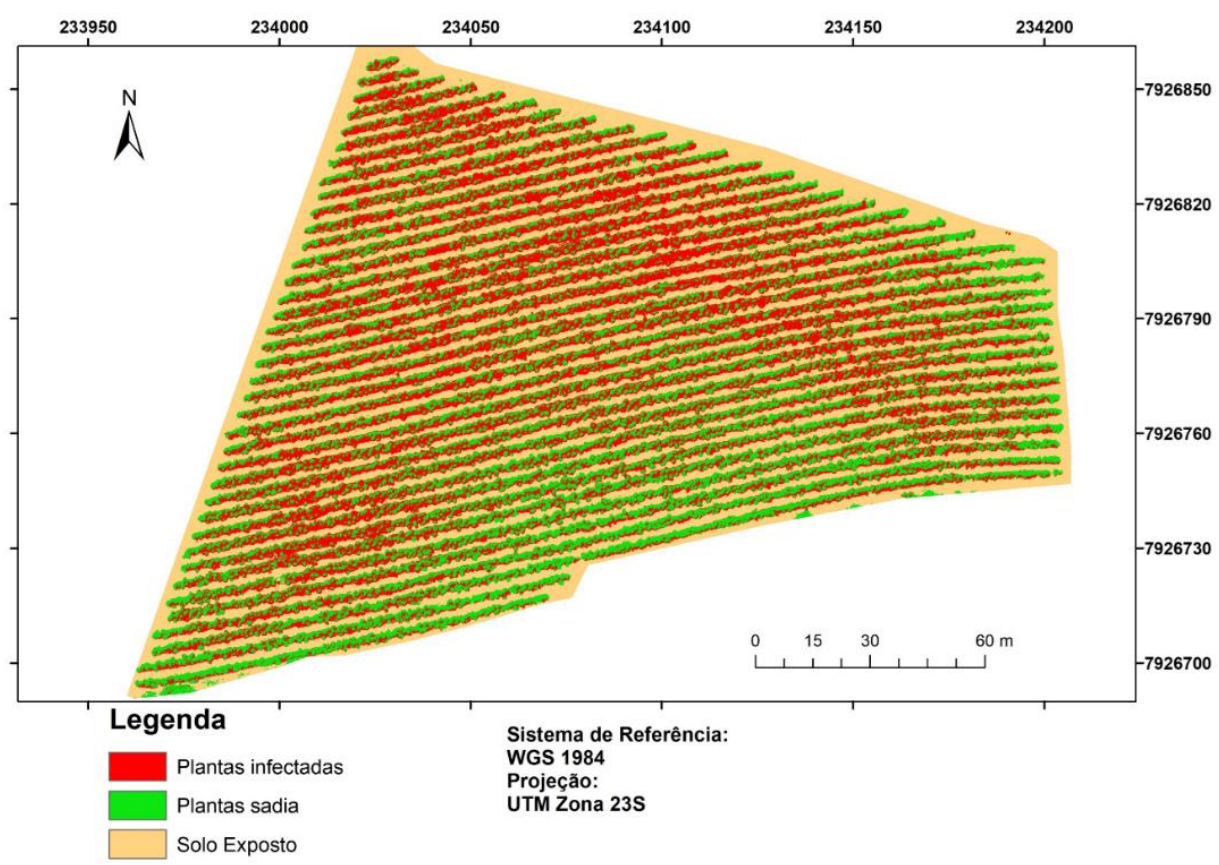

Fonte - Os autores. 
Através da Figura 6, é possível observar principalmente duas "manchas" com maior concentração de nematoides. Uma paralela ao final das linhas de plantas de cafeeiro, no canto superior direito, e outra começando no canto inferior esquerdo. É possível observar o espaçamento entre as linhas de café bem definidas, que retrata a delimitação do solo exposto.

A matriz de confusão gerada para subsidiar a análise qualitativa da classificação foi disposta na Tabela 2. O processo de distribuição das classes, assim como o número de pontos de controle segue o mesmo apresentado anteriormente para o mosaico RGB.

Tabela 2 - Matriz de confusão para a classificação MAXVER com os erros de comissão e omissão, para imagem Mapir.

\begin{tabular}{cccccc}
\hline Classe & $\begin{array}{c}\text { Plantas } \\
\text { sadias }\end{array}$ & $\begin{array}{c}\text { Plantas } \\
\text { infectadas }\end{array}$ & Solo Exposto & Total & Comissão (\%) \\
\hline Plantas sadias & 11 & 1 & 0 & $\mathbf{1 2}$ & 8,33 \\
Plantas & 2 & 16 & 0 & $\mathbf{1 8}$ & 11,11 \\
infectadas & 1 & 3 & 10 & $\mathbf{1 4}$ & 28,57 \\
Solo Exposto & 1 & $\mathbf{2 0}$ & $\mathbf{1 0}$ & $\mathbf{4 4}$ & \\
Total & $\mathbf{1 4}$ & $\mathbf{2 0}$ & 0,00 & & \\
Omissão (\%) & 21,42 & 20,00 & &
\end{tabular}

Fonte - Os autores.

Através dos resultados da Tabela 2 contata-se que os melhores resultados foram obtidos pela classe solo exposto, uma vez que esta classe não apresentou nenhum erro de omissão, e teve todos seus pixels classificados de forma correta. As áreas com plantas sadias apresentaram o maior erro de omissão $(21,42 \%)$, sendo que desta classe foram classificados de forma incorreta três pontos de controle, distribuídos entre solo exposto (um ponto de controle) e 'Plantas infectadas' (dois pontos de controle). A classe 'Plantas infectadas' por nematoides, apresentou resultados intermediários, sendo o erro de omissão igual a $20,00 \%$, observa-se que a maioria dos seus pontos de controle que foram classificados de forma incorreta relacionou-se com a classe solo exposto, sendo ao todo três, e apenas um com a classe 'Plantas sadias'.

O menor erro obtido pela classe de solo exposto pode ser explicado por esta pertencer a uma classe espectral bem definida e diferente das classes contendo plantas sadias e infectadas. Para Tisot et. al (2007), em se tratando de classes com assinaturas espectrais bem distintas, a separação do classificador MAXVER é executada de forma satisfatória, mesmo em imagens com resolução espectral não muito elevada.

Nota-se redução de precisão do classificador ao observar as classes 'Plantas sadias' e 'Plantas infectadas', que tiveram precisão de $78,58 \%$ e 80,00 , respectivamente. Estes resultados se comparados com o resultado encontrado na classe solo exposto, são levemente inferiores. Neste contexto, faz-se extremamente necessário as visitas de campo para possuir maior controle das variáveis mapeadas em sensores com baixa resolução espectral, uma vez que imagens com bandas que possuem largas faixas espectrais podem apresentar dificuldades na separação de determinados alvos espectrais (CICCONET, 2017). Contudo, analisando a quantidade de pontos classificados corretamente, a precisão do classificador para as classes "Plantas sadias' e 'Plantas infectadas' é considerável.

Analisando a acurácia do usuário observa-se que o menor erro de comissão foi da classe 'Plantas sadias', sendo este igual $8,33 \%$ o que implica numa precisão de $91,66 \%$, o único valor classificado de forma incorreta foi atribuído a classe "Plantas infectadas". Essa classe apresentou mais uma vez um valor de erro intermediário, sendo igual a $11,11 \%$, os valores classificados de forma errada foram associados a classe 'Plantas sadias', sendo ao todo dois pontos. Em contrapartida ao erro de omissão, a classe solo exposto apresentou maior erro de comissão, sendo o erro igual a $28,57 \%$; ao todo foram 4 pontos classificados de forma errada, sendo 3 na classe "Plantas infectada' e 1 na classe 'Plantas sadias".

$\begin{array}{llllll}\text { Caminhos de Geografia } & \text { Uberlândia-MG } & \text { v. 21, n. } 76 & \text { Ago/2020 } & \text { p. } 72-84 & \text { Página } 82\end{array}$


Para constatar a validade da classificação também foram determinados os valores de índice Kappa e exatidão global, sendo eles iguais a 0,75 e $84 \%$, respectivamente. De acordo com os valores de referência da Tabela 1, através do Kappa obtido pode-se determinar a classificação como "Muito Boa", uma vez que seu valor está compreendido entre 0,6 e 0,8 , como mostra a Tabela 1 . O valor de exatidão global também retornou um valor significativo, sendo este um pouco maior que o índice Kappa, já que ele é menos criterioso no seu cálculo.

Ao analisarmos o comportamento das duas câmeras, durante a classificação, infere-se que os melhores resultados são advindos do sensor Mapir. Os resultados da matriz de confusão apontem porcentagem de erro levemente menor neste sensor (comissão e omissão), sendo que a classe plantas infectadas apresenta erros de confusão relacionados com apenas com as plantas sadia, ao passo que no sensor acoplado ao drone, os erros dessa classe ficam relacionados com o solo exposto e as plantas sadias.

\section{CONSIDERAÇÕES FINAIS}

A aplicação de ARPs na detecção de patógenos vem crescendo cada vez mais, uma vez que esta tecnologia se tem mostrado eficiente em pesquisas agrícolas que as utilizam. Através do mosaico das imagens aerofotogramétricas, é possível identificar com exatidão aspectos físicos ligados à plantação, já que é possível obter o GSD que melhor atenda as análises de cada cultura. Dessa forma, a classificação pelo método de Máxima Verossimilhança mostrou-se eficiente na detecção de nematoides, alcançando os resultados esperados. No que tange a aplicabilidade do método, sua eficiência foi comprovada pelo índice Kappa, que retornou um valor próximo a um, sendo este um resultado "muito bom", nos dois casos analisados, segundo as referências utilizadas nessa pesquisa. O índice de precisão geral retornou valores mais otimistas, visto as referências que são adotadas para o seu cálculo. Todavia, a metodologia ainda pode ser aperfeiçoada em pesquisas posteriores, para que o resultado seja mais acurado, assim como a comparação entre outros métodos de classificação, para estimar o mais preciso, ou determinar um valor limiar mais próximo do ideal.

\section{REFERÊNCIAS}

ARCGIS. The mapping and analytics platform. Disponível em: <https://www.esri.com/enus/arcgis/about-arcgis/overview >. Acesso em: 18 de maio de 2020.

ARRUDA, R. O. A produção de café arábica e sua relação com o crédito rural nos principais estados produtores do Brasil. 2017. 21 f. TCC (Graduação em Ciências Contábeis) - Faculdade de Ciências Contábeis, Universidade Federal de Uberlândia, Uberlândia, 2017.

BECK, P. S. A. et al. The feasibility of detecting trees affected by Pine Wood Nematode using remote sensing. Europe Comission. Joint Research Centre. Institute of Environment and Sustainability, Italy. 2015.

CAMPOS VP, VILLAIN L. Nematode parasites of coffee, cocoa and tea. In: LUC, M.; SIKORA, R.A.; BRIDGE, J. (Eds.) Plant parasitic nematodes in subtropical and tropical agriculture. Cambridge: $\mathrm{CABI}$ 1990. https://doi.org/10.1079/9780851997278.0529

p. 529-579.

CICCONET, N. Mapeamento das áreas de ocorrência de infestação do eragrostis plana nees (capim annoni) com sensoriamento remoto: estudo de caso em Santana do Livramento/ RS/ Brasil. 2017. 81 f. Dissertação (Mestrado em Geografia) - Centro de Ciências Naturais e Exatas, Universidade Federal de Santa Maria, Santa Maria, 2017.

COHEN, J. A coefficient of agreement for nominal scales. Educational and Psychological

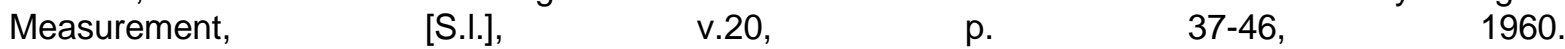
https://doi.org/10.1177/001316446002000104

DAMIAN et al. O uso de Aeronaves Remotamente Pilotadas (RPAS) na agricultura. In: SANTI, A. L. (Org.). Agricultura de precisão no Rio Grande do Sul. Santa Maria: CESPOL, 2016. p. 285-309.

EMBRAPA - Empresa Brasileira de Pesquisa Agropecuária. Estudos socioeconômicos e ambientais Produtividade média da cafeicultura brasileira em 2018. 2018. Disponível em: $<$ https://www.embrapa.br/busca-de-noticias/-/noticia/31412007/produtividade-media-da-cafeicultura-

$\begin{array}{lllll}\text { Caminhos de Geografia } \quad \text { Uberlândia-MG } & \text { v. 21, n. } 76 \quad \text { Ago/2020 } & \text { p. } 72-84 & \text { Página } 83\end{array}$



Bruno Sérgio Vieira

brasileira-em-2018-devera-ser-a-maior-ja-registrada-com-2947-sacas-por-hectare>. Acesso em: 21 de novembro de 2018.

ENVI. Environment for Visualizing Images. Disponível em: < http://www.envi.com.br/ >. Acesso em: 18 de maio de 2020.

FERRAZ, G. A. S.; SILVA, F. M.; COSTA, P. A. N. da; SILVA, A. C.; CARVALHO, F.M. Agricultura de precisão no estudo de atributos químicos do solo e da produtividade de lavoura cafeeira. Coffee Science, Lavras, v. 7, p. 59-67, 2012.

INPE - Instituto Nacional de Pesquisas Espaciais. Tutorial SPRING. 2002. Disponível em: $<$ http://www.dpi.inpe.br/spring/portugues/tutorial/index.html>. Acesso em: 10 de outubro de 2018.

ITO, D.S.; MACHADO, A.C.Z.; SILVA, S.A. Distribuição de espécies de nematoides do gênero Meloidogyne em regiões cafeeiras do Paraná. Ciência Florestal, Santa Maria, v. 1, p.113-124, 2012.

KOHAVI, R.; PROVOST, F. Glossary of terms. Machine Learning, Boston, v. 30, p. 271-274, 1998. https://doi.org/10.1023/A:1017181826899

MAPPIR. Mappir Camera Control (MCC). Disponível em: <https://www.mapir.camera/products/mapircamera-control>. Acesso em: 18 de maio de 2020.

MARTINS, G. D.; GALO, M. de L. B. T. Detecção de áreas infestadas por nematoides e Migdolus fryanus em cultura canavieira a partir de imagens multiespectrais Rapideye. Revista Brasileira de Cartografia, Rio de Janeiro, v. 66, p.285-301. 2014.

Caracterização hiperespectral in situ do cafeeiro infectado por nematoides. In: XVII Simpósio Brasileiro de Sensoriamento Remoto - SBSR, 2015. João Pessoa - PB. Anais... São Jose dos Campos - SP: Instituto Nacional de Pesquisas Espaciais, 2015, p.1829-1836.

MCKINNON, T.; HOFF, P. Comparando Índices de Vegetação Baseados em RGB com o NDVI para Imagens Drone Agrícolas. Agribotix.com, p. 1-6. 2017. Disponível em: < https://agribotix.com/blog/2017/04/30/comparing-rgb-based-vegetation-indices-with-ndviforagricultural-drone-imagery/ >. Acesso em: 15 maio 2019.

PIX4D. PIX4DMapper: documentation. Disponível em: <https://support.pix4d.com/hc/enus/categories/360001503192-Pix4Dmapper>. Acesso em: 18/05/2020.

PONZONI, F.J.; SHIMABUKURO, Y.E.; KUPLICH, T.M. Sensoriamento Remoto da Vegetação. 2. ed. São Paulo: Oficina de Textos, 2012.

OLIVEIRA, G. S. de. Produtividade de biomassa de cana-de-açúcar em função dos índices de vegetação utilizando técnicas de sensoriamento remoto. 2015. 80 f. Dissertação (Mestrado em Agronomia) - Faculdade de Ciências Agrarias e Veterinárias, Universidade Estadual Paulista, Jaboticaba, 2015.

QUEIROZ, R. B.; RODRIGUES, A. G.; GÓMEZ, A. T. Estudo Comparativo entre as Técnicas Máxima Verossimilhança Gaussiana e Redes Neurais na Classificação de Imagens IR-MSS CBERS 1. In: II Workshop de Tecnologia da Informação Aplicada ao Meio Ambiente - CBcomp, 2004, Palhoça, SC. Anais... Palhoça, SC 2004. p. 746-749

SILVA, C.R.; MACHADO, S.L.D.; ARAUJO, A.A.; ABREU JUNIOR, C.A.M.; Analysis of the phenology dynamics of Brazilian caatinga species with NDVI time series. CERNE, Lavras, v.24, p.48-58. 2018. https://doi.org/10.1590/01047760201824012487

TISOT, Daniela A. et al. Eficácia de dados Hyperion/EO-1 para identificação de alvos agrícolas: comparação com dados ETM+/Landsat-7. Eng. Agrícola, Jaboticabal, v. 27, p. 511-519. 2007. https://doi.org/10.1590/S0100-69162007000300021

ZAMBOLIM, L. Doenças do cafeeiro. In: Amorim, L.; Rezende, J. A. M.; Bergamim Filho, A.; Camargo, L. E. A. (Eds) Manual de fitopatologia: doenças das plantas cultivadas, São Paulo: Ceres, 2016. p. 165-180.

Recebido em: 25/10/2019

Aceito para publicação em: 05/06/2020 